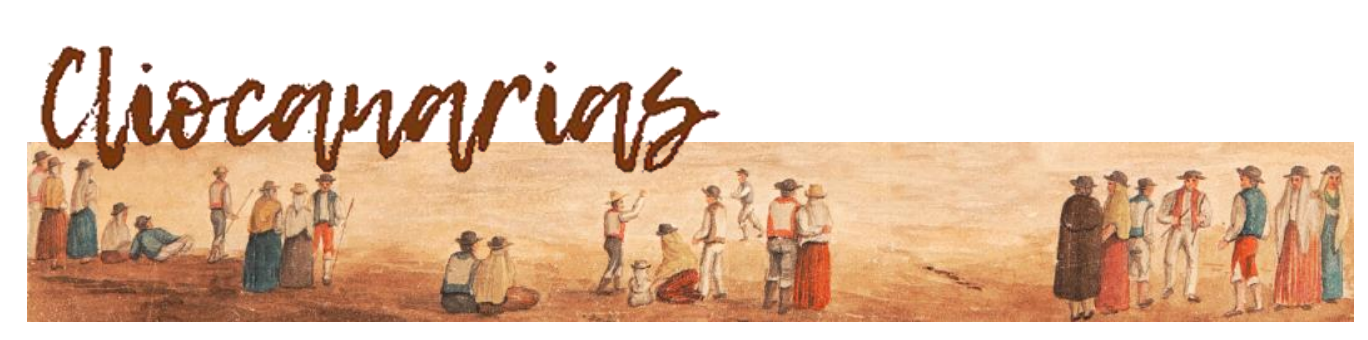

ISSN 2695-4494

https://doi.org/10.53335/cliocanarias.2021.3.25

\title{
DE ISLA EN CONTINENTE, CATÁLOGO Y EXPOSICIÓN SOBRE VIERA Y CLAVIJO EN MADRID
}

DE ISLA EN CONTINENTE, CATALOG AND EXHIBITION ABOUT VIERA Y CLAVIJO IN MADRID

Manuel de PAZ SÁNCHEZ*

Once hombres y dos mujeres suscriben doce capítulos en el libro a que nos referiremos en los siguientes párrafos. Se trata del catálogo de la exposición sobre la vida y obra de José de Viera y Clavijo (1731-1813) ${ }^{1}$, que se celebró en la Sala Hipóstila de la Biblioteca Nacional de España, en Madrid, entre el 25 de enero y el 5 de mayo de 2019. Según datos de la propia BNE, durante este tiempo la muestra fue visitada por 15.288 personas, incluyendo grupos de diversos centros de enseñanza secundaria e infantiles. He aquí un gráfico con cinco exposiciones diferentes (aunque las otras cuatro estuvieron menos tiempo), escogidas al azar, en las que se expone una comparativa que permite mostrar que, si bien la exposición sobre Viera no puede considerarse un éxito absoluto, tampoco dejó de interesar a la ciudadanía de la capital del reino:

MUESTRA DE VISITANTES 2003-2019

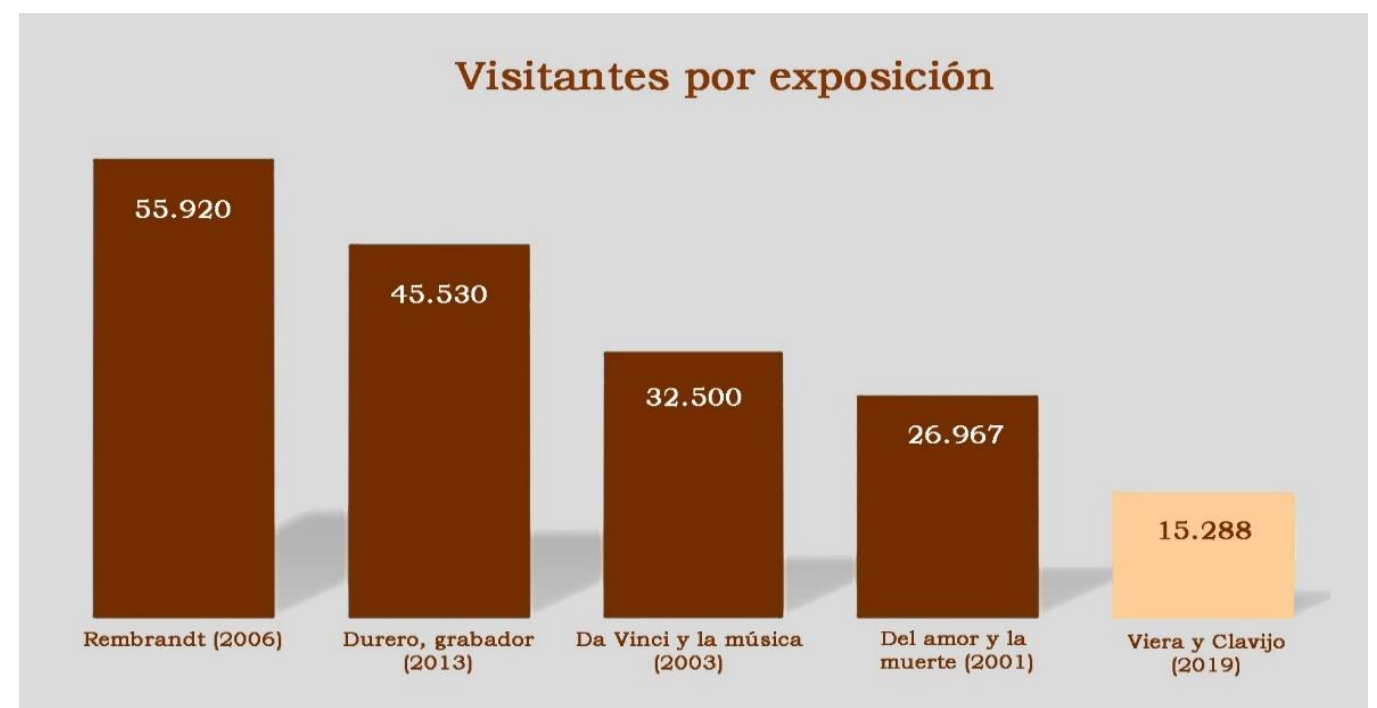

Fuente: https://www.abc.es/espana/madrid/abci-tricentenario-biblioteca-expo201204270000_noticia.html

https://www.hoyesarte.com/exposiciones-artes-visuales/museos/mas-de-150-000-visitantes-han-recorrido-las-exposiciones-del-bne-en-2013_148043/

\footnotetext{
* Catedrático de Historia de América de la Universidad de La Laguna. https:/ / orcid.org/00000002-9556-9157 (mdepaz@ull.edu.es).

${ }^{1}$ PADRÓN FERNÁNDEZ, Rafael (Ed.): Viera y Clavijo. De isla en continente, Madrid: Gobierno de Canarias y Biblioteca Nacional de España, 2019, 539 págs.; ISBN: 978-84-17764-23-4.
} 
Las autoras y autores de la obra colectiva en cuestión, con los respectivos títulos de sus aportaciones, son las que siguen: I. Joaquín Álvarez Barrientos: "José de Viera y Clavijo (1731-1813). Imagen de un hombre de letras cortesano"; II. Alfonso Soriano y Benitez de Lugo: "Los ilustrados canarios del siglo XVIII en la Villa y Corte»; III. Francisco Fajardo Spínola: "Viera y Clavijo y la Historia de Canarias»; IV. Santiago de Luxán Meléndez: "La biblioteca canaria de José de Viera y Clavijo (1733-1813)»; V. Rafael Padrón y Juan Manuel Ló-

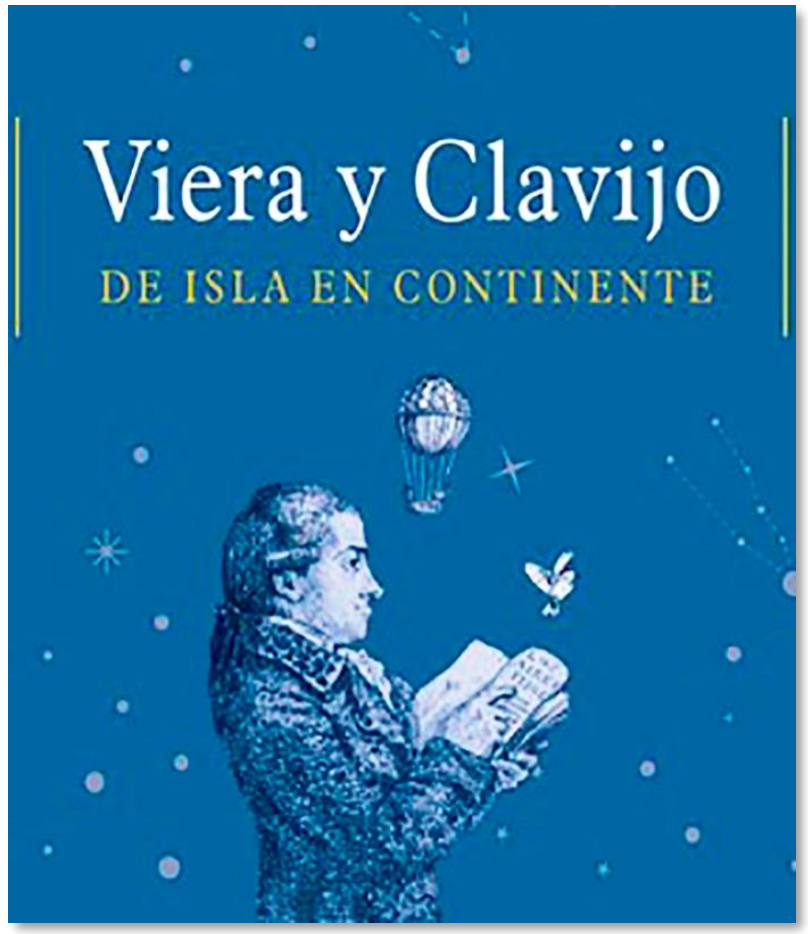
pez: "Qvod Natura Nobis Dat: El Diccionario de Historia Natural de las Islas Canarias, de Viera y Clavijo"; VI. Cristóbal Corrales y Dolores Corbella: "Diatopismos léxicos en la obra de Viera y Clavijo"; VII. Olegario Negrín Fajardo: "La perspectiva educativa ilustrada de José de Viera y Clavijo"; VIII. Juan José Laforet: "Viera y Clavijo, comunicador y protoperiodista canario"; IX. Julio Sánchez Rodríguez: "Viera y Clavijo: religión y cultura, fe y razón»; X. Victoria Galván González: "La literatura de Viera y Clavijo"; XI. José Cebrián: "Ciencia experimental y poesía didáctica en Viera y Clavijo"; y XII. Rafael Padrón: "Europa a la vista: Viera y Clavijo en el Grand Tour".

Se echan en falta, pues, algunas autoras que, en mi opinión, deberian haber participado en el evento o, al menos, en el libro, que como queda dicho es una compilación de trabajos y cosas. Entre esos nombres femeninos que no figuran en el catálogo me gustaría mencionar a la profesora Yolanda Arencibia, autora, precisamente, de la exhaustiva entrada sobre Viera y Clavijo en el Diccionario biográfico español que no ha mucho publicó la Real Academia de la Historia, entre otras varias aportaciones de interés sobre el personaje y sus contextos histórico-literarios. También, entre los varones, brilla por su ausencia el catedrático Manuel Hernández González, autor de una obra pionera y, en varios aspectos, esencial sobre los rasgos básicos de la Ilustración en Canarias, publicada hace más de tres décadas con una tirada de más de diez mil ejemplares, bajo el título de La Ilustración. Asimismo, han realizado aportaciones de interés, en relación con Viera y su época, otros autores como Santana o Guimerá, cuya participación hubiese enriquecido la obra.

En cualquier caso, no cabe duda de que este tipo de acciones - tanto la exposición como la publicación del catálogo- son necesarias y deben ser aplaudidas e imitadas, y, asimismo, debo confesar de corazón que siempre me parecerá poco todo lo que se haga para festejar, aquende y allende, la figura del gran ilustrado canario José de Viera y Clavijo, un personaje extraordinario 
al que he consagrado, durante años, algunas de las páginas que más satisfacción me han producido a lo largo de mi vida profesional. Ahora bien, toda reseña científica que se precie debe comprender también una cierta dimensión crítica, especialmente si con ello se contribuye a corregir algún error o a reflexionar sobre cuestiones no carentes de interés en relación con el biografiado y con su época. Señalaré solo algunos yerros y omisiones que, en mi opinión, podrian revestir cierta importancia.

El capítulo redactado por el profesor e investigador Joaquín Álvarez Barrientos, sin duda un estudio muy meritorio por su esquema abarcador y ambicioso en sus objetivos, me inspira, en primer lugar, una duda razonable: ¿hablamos de la España del Antiguo Régimen y del Siglo de las Luces, o más bien de la España contemporánea del siglo XIX y de la primera mitad del XX? Me explico. La visión de un centro, la villa y Corte, y una serie de provincias de, digamos, segundo orden, se corresponde más bien con una concepción centralista, mesetaria y burguesa más propia del siglo XIX que con la de una capital imperial, como pretendió ser Madrid entre dos hemisferios, aún a lo largo del siglo XVIII y a pesar del creciente poder de las ciudades criollas, es decir, hasta la pérdida de la América continental española. Estaban en apogeo, a pesar de las crisis coyunturales, los virreinatos, las capitanías generales, las audiencias, los obispados; se trataba de una España, tal vez de una Hispanidad, múltiple y diversa, rica, colorista, abierta, plural, bella, y, justamente en este contexto, Viera hablaba de España cuando se refería a la $\mathrm{Pe}-$ nínsula. Así es. En las islas Canarias son centenares, por no decir miles, las referencias que se pueden espigar en los protocolos notariales de los siglos XVII y XVIII en los que todo el mundo se refiere a España, a la Península, como "España" y los "reinos de España", pues todo el territorio, el inmenso territorio hispano-americano-filipino se mantenía unido en la figura sagrada del monarca. Lo otro, lo de hablar de la capital y de las provincias es posterior, vino con la decadencia, lo mismo que el invento de lo local frente a lo nacional. No puedo extenderme como me gustaría en este tema, pero, como ya escribí en la "Introducción" de mi edición crítica de la Historia de Canarias de Viera y Clavijo, una de las obras que dio fama y reconocimiento a William Robertson (el admirable Robertson, como le llamaba Viera) fue precisamente una, digamos, historia regional, la Historia de Escocia, que el canario pudo leer en francés en la década de 1760, cuando preparaba la primera versión, esto es, el borrador de su Historia. En resumen, en la mente de Viera, cuando escribió su Historia de Canarias, al margen de la utilización de técnicas y métodos historiográficos que estaban en boga en aquellas fechas, no existía solamente la convicción de que pretendía ensalzar a su terruño y buscarle un lugar en el mapa de Europa o del mundo; en su cabeza bullía la idea de que estaba prestando un servicio extraordinario no solo a la tierra en la que había nacido y a la que regresó satisfecho a pasar sin estrecheces los últimos años de su vida, sino a la historia como disciplina en general, a la propia historia de la humanidad. Se trataba de un territorio único, con un origen singular que, por si fuera poco, poseía un pueblo indigena "propio", al contrario que el resto de los archipiélagos macaronésicos, y que encima se situaba en mitad de los mares, un oasis para los navegantes y viajeros desde la época del descubrimiento. 
Pongo un ejemplo que creo significativo del proyecto historiográfico del historiador canario. Cuando Viera comparó las conquistas de Canarias y de América o, mejor dicho, las de los indígenas de Gran Canaria con los indoamericanos, escribió no sin cierta dureza en una época que, además, es la del gran debate internacional sobre el "buen salvaje», el de las polémicas sobre la influencia del medio natural en las razas, la degeneración y, digamos, de la proto-evolución que el canario atisba, directamente, en sus lecturas del conde de Buffon (a quien, justamente, tradujo su pariente José Clavijo y Fajardo), lo siguiente:

Así, aunque las conquistas de México y del Perú (a que abrió camino la de la Gran Canaria), se parecieron mucho a ella en las disensiones de Cortés y Velázquez, de Almagro y de Pizarro, de Rejón y Bermúdez, porque Cortés fue enviado preso a España como Rejón, y Almagro degollado en un cadalso como Algaba por su rival (no siendo la tierra sino un teatro, donde se representan las mismas tragedias bajo de nombres diferentes); no obstante esto, digo que fueron muy desemejantes estas conquistas en la naturaleza de los paises y en el genio de las naciones. México y el Perú eran dos imperios vastos, opulentos y bastantes a componer un Nuevo Mundo. Canaria solo era una isla de cuarenta y ocho leguas de circunferencia, pobre de minas de oro y plata. Los indios componian un linaje de hombres [...] pusilánimes, perezosos y que temian y adoraban a los europeos, y aun a los caballos como a divinidades; los canarios una gente robusta, endurecida, llena de coraje, incapaz de miedo, inclinada a la guerra y que despreciaba altamente a sus enemigos. Véase aqui en lo que Pedro de Vera pudo ser superior a Cortés y Pizarro (Viera, Historia, II, VII, § XLIX).

Respecto a la opinión de Viera sobre la ciudad de Madrid, creo que se puede afirmar que, si hubiese podido elegir entre vivir en la villa del Oso y del Madroño o hacerlo en París, habría elegido con seguridad la capital francesa, al menos durante los mismos años en los que residió en la península ibérica. Sus críticas a la villa y Corte, a pesar de los pesares, son indiscutibles. En mi trabajo "Un orientalista en Viena. Las cartas inéditas (1781-1783) de Isidoro M. Bosarte a José de Viera y Clavijo", se leen, por ejemplo, estos párrafos en la epístola que el canario le remitió a Bosarte, el 8 de marzo de 1782:

Crea Vm. que, para quien tiene algún conocimiento del mundo, de los hombres y aun de las mujeres, no hay más que dos cosas: o pedir sus inválidos y retirarse a pasar el invierno de la vejez a las Islas Beatas de los poetas en figura de arcediano de Fuerteventura, o irse a Alepo y Esmirna a hablar el árabe como Vm. pretende y formar su serrallo de las huries de ojos negros.

Entre tanto, no le hablaré a Vm. en este correo de nuestras noticias militares ni de las politicas, pues ellas van por sus pasos contados al cuarto del señor embajador. Tampoco hablaré de las literarias, porque en España no las hay dignas de Vm. ni de mi [...]. Tampoco diré a Vm. nada de novedades eclesiásticas, porque solo sé que nuestras capillas y corbatas devotas andan alborotadas con las providencias que, les cuentan, ha tomado el Emperador en ese pais sobre frailes, monjas, procesiones, judios, dispensas, votos y demás cositas que levantan la gente en peso, a que se 
añade el extraño viaje del Papa a esa corte. Pero las personas sensatas no dejan de llevarle en cuenta a José II los muchos curatos que ha establecido, su instrucción, su popularidad, su amor al buen orden, con las demás raras prendas que adornan su persona. Yo a lo menos hablaré siempre bien de un principe, que me habló con tanto agrado, cuando le fui presentado por nuestro embajador.

¿Y qué diré a Vm. sobre novedades económicas? Que se ha plantificado un Banco Nacional y que se ha distribuido un indulto de Roma para poder comer de carne en la cuaresma, con un edificativo sumario de los precios respectivos al carácter y bolsillo de los carnivoros que lo tomen. ¿Y de novedades de politica? Que se ha compuesto en la Puerta del Sol la fuente de Mariblanca; que se ha adornado el Prado con otra muy pesada del carro de Cibeles; que han puesto en otra, no menos monstruosa, un Apolo de Belvedere y que se están fabricando dos fuentes más, para que haya cuatro.

iQué falta me hace un poco de Vm. para pensar cosas nuevas y ver la creación de ideas no encontradas! Porque, amigo, aqui no hay quien delire. Todo es letargo o Coma somnolenta como dicen los médicos.

Se detectan también ciertos yerros, sin duda involuntarios, en el estudio del profesor Álvarez Barrientos. En la página 67, por ejemplo, escribe lo siguiente en referencia, claro está, a José de Viera y Clavijo: Cuando en 1782 vio que no le quedaban opciones, pretendió el cargo de arcediano de la catedral de Fuerteventura, que consiguió inmediatamente, pero aún demoró dos años más el regreso, que se verificó en 1784. No hubo tal catedral en la maravillosa y sufrida isla de Fuerteventura, concretamente en Betancuria, aunque, es cierto que se produjo un intento de erección episcopal que no fructificó, pero esto tuvo lugar en torno a 1428. El propio Viera le dedicó un epígrafe a este curioso asunto (Viera, Historia, IV, XVI, § XIII: "Bula de erección de un nuevo obispado en Fuerteventura"). El polígrafo fue, como es bien sabido, arcediano de Fuerteventura en la catedral de la diócesis canariense, en Las Palmas de Gran Canaria, único obispado del Archipiélago en la época de su nombramiento, aunque más tarde, en 1819 , se erigió la diócesis nivariense, la de la actual provincia de Santa Cruz de Tenerife, y esta sigue siendo la situación actual.

Además, en la misma página, en la cita que se hace a la carta que le remitió Viera al marqués de San Andrés, el 28 de junio de 1782, hay dos errores. En las líneas cuatro y cinco del sangrado, donde dice: En Madrid, es dificil fuese pronunciado a la naturaleza de mis méritos..., en realidad debe leerse: En Madrid, es dificil fuese proporcionado a la naturaleza de mis méritos; y, más abajo, cuando afirma Viera: Así he pensado pasar mis últimos años..., la carta original pone días, en lugar de años; pero estas son minucias sin importancia. Mucho peor hubiese sido que, por alguna circunstancia, el autor del capítulo que venimos comentando se hubiese referido a otros párrafos apócrifos de este epistolario de Viera, en el que, por ejemplo, se leen algunas frases peregrinas. Así, en las páginas 118-119, se dice: El inspector ha empezado a comunicarme algunos papeles que extractar. Está bueno y gordo entre sus mamotretos y libros de Historia Brantina, expresión ciertamente extraña. Pero, en realidad, lo 
que escribe Viera, según el original, es Bizantina en lugar de Brantina. O cuando, al hablar Viera de José Antonio Vandewalle de Cervellón (Santa Cruz de La Palma 1734-1811), en relación con la localización en Madrid de la comedia de Lope, Los guanches de Tenerife y conquista de Canarias, se lee respecto al palmero: Esta comedia, que encontramos citada en el autor de la Biblioteca Indiana, la descubrió Vandewalle por encargo mio en la Real Biblioteca y en la de los carmelitas descalzos [...]. Avisómelo, encarguele una copia, me la ofreció, pero después acá se ha ido retirando, no me ha dado la copia ni aún para leerla, me ha ocultado [el pensamiento de reimprimirla; ha olvidado] el expediente de los ducados y sabe Dios el batiborrillo de especies y fárragos acapuchinados que dará a luz si logra sus intentos. He puesto entre corchetes el trozo que no figura en la transcripción de esta carta de Viera, que está datada en Madrid a 9 de abril de 1776. Pero no vamos a proseguir por este camino, pues es frecuente que se cometan algunas pifias y omisiones en todo trabajo de transcripción y, como dice un admirado amigo y editor canario, todos los libros contienen errores.

Aparte del notable ensayo del profesor Álvarez Barrientos, también llama la atención el estudio del señor Alfonso Soriano sobre los ilustrados canarios del siglo XVIII (evidentemente), en la capital de España. Son todos los que están, pero no están todos los que son. Constan los más conocidos, como los Iriarte, Agustín Ricardo Madan o José Clavijo y Fajardo, entre otros, como por ejemplo el sobrino-nieto de Amaro Pargo, Francisco Xavier Machado Fiesco. Pero tal vez debieron trazarse algunos renglones biográficos sobre personajes de indudable enjundia, como Antonio José Álvarez de Abreu, primer marqués de la Regalía, creado como tal por Felipe V, amigo por cierto del citado Amaro Rodríguez Felipe, quien lo trasladó a Venezuela en el barco que estaba a sus órdenes en 1714. También debió merecer un lugar prominente en este parnaso afortunado la singular figura de don Cristóbal del Hoyo Solórzano, autor precisamente de una obra capital, Madrid por dentro (1745), y yo creo que asimismo debieron formar parte de este elenco ilustrado, entre otros varios isleños que en algún momento de sus vidas residieron en Madrid, personajes como el propio Vandewalle, antes citado, amigo, colaborador y, en ocasiones, crítico moderado del propio Viera y Clavijo, a quien en el fondo admiraba profundamente; y, por supuesto, Amaro José González de Mesa, el sobrinísimo de Amaro Pargo, otro personaje esencial que contribuyó a la consecución de empresas ilustradas como la fundación de la Real Sociedad Económica de Amigos del País, en La Laguna, cuyos estatutos fundacionales contribuyó a redactar y que, muchos años antes, había sido rector en Salamanca y jurista en Madrid, todo ello en vísperas de su retorno definitivo a Tenerife, donde junto a su prima hermana y esposa, Ana Josefa Rodríguez Felipe, heredó la gran fortuna de su tío el corsario, Amaro Pargo.

En relación con lo anterior es preciso subrayar que el mismo Viera se refirió a algunos de ellos en su "Biblioteca de autores canarios", al final del tomo IV de su Historia, como el citado Antonio José Álvarez de Abreu, autor de Victima real legal, o el también mencionado Amaro José González de Mesa, de quien dijo, en el volumen III de su Historia, que se trataba de un ciudadano de grandes talentos y recursos (Historia, III, XV, § LXXX). 
Son varios los trabajos contenidos en este volumen que, en relación con el ámbito de la historiografia, la bibliografia o la labor literaria - como autor y como traductor - de José de Viera y Clavijo merecerian una atención pormenorizada, pero no disponemos de espacio para ello, al margen de otras áreas de conocimiento que acreditan, desde luego, un tratamiento singular. La valiosa contribución del profesor Francisco Fajardo sobre la Historia de Viera destaca, entre otros aspectos, por el gran esfuerzo de síntesis realizado por el autor, cuya aportación consta de los siguientes epígrafes: "El autor y su obra", "La necesidad de la Historia", "Una historia nueva", "El plan de la obra", "Las fuentes", "Los buenos guanches", "Canarias, América y el Atlántico", "Contra los prodigios" y "Posición socio-ideológica". La reproducción autógrafa en anexo de la Oración gratulatoria de Viera, otorga, si cabe, un mayor realce a este capítulo.

Es sugerente, asimismo, el ensayo que sobre la biblioteca canaria de Viera se incluye en las páginas 163-211 por el profesor Santiago Luxán, y que resume la colección de libros que llegaron o pudieron llegar a manos del arcediano entre 1733 y 1813, es decir, desde que alcanzó los dos años de vida hasta el de su fallecimiento. El autor sostiene que su biografia se articula en torno a los libros, describe las colecciones a las que accede el poligrafo, subraya la biblioteca canaria del abate, que incluye naturalmente la dimensión eclesiástica, y, en fin, otros aspectos singulares como la "geografia y etimología fantástica". El trabajo culmina con una selección de obras de cronistas, memorialistas, etc., representativos del acervo historiográfico isleño.

El Diccionario de Historia Natural de Canarias, como ya se apuntó al principio, es otro de los epígrafes que merece una especial mención, así como el enjundioso capítulo referido a los "Diatopismos léxicos", que corre a cargo de Cristóbal Corrales y Dolores Corbella. Una larga trayectoria sobre temas de historia de la educación avala el trabajo de Olegario Negrín sobre la "perspectiva educativa ilustrada" en Viera y Clavijo, y otro tanto puede decirse del estudio que realiza Juan José Laforet sobre el "protoperiodismo" de nuestro autor, en cuya página 327 se reproduce, por cierto, un conocido retrato de don Cristóbal del Hoyo, ya mencionado. Se ocupa de los aspectos religiosos don Julio Sánchez Rodríguez, autor de un libro de divulgación sobre el polígrafo y su dimensión eclesiástica. Quizás hubiese estado bien alguna alusión a la edición impresa de El Hieroteo, que se publicó hace años en Santa Cruz de Tenerife, y que el obispo nivariense, don Bernardo, presentó en su día en la Real Sociedad Económica de Amigos del País de Tenerife, en La Laguna, pero un trabajo de sintesis no puede abarcarlo todo.

Victoria Galván realiza, por su parte, un documentado ensayo sobre "La literatura de Viera y Clavijo", tema que en su dia constituyó su tesis doctoral. Se recogen en este capítulo reproducciones de la traducción y recreación del polígrafo sobre los poemas de Jacob Delille (El Amador de los Campos o las geórgicas de Jacob Delille, que se custodia en El Museo Canario, y, asimismo, de la "versión lacunense", El hombre en los campos o las geórgicas de Jacob Delille, que figura en la Económica tinerfeña). José Cebrián, por su lado, estudia la poesía didascálica en relación con la ciencia, en línea con la excelente 
edición de Los aires fijos, publicada en su día por este autor. Finalmente, orlado de numerosas estampas a toda página, el comisario de la exposición, Rafael Padrón Fernández, resume en un ensayo ad hoc diversos aspectos de las singladuras por Europa de Viera y Clavijo.

La colección de ilustraciones de la obra resulta, en efecto, muy atractiva, fiel reflejo de la exposición que tuvimos el placer de visitar en la Sala Hipóstila de la Biblioteca Nacional. La "Casa y jardines de Franchy", de S. Cattoir o, concretamente, en las páginas 303-305, la reproducción de algunas hojas del manuscrito del propio Viera: Noticias del cielo o astronomía para niños, 1807, perteneciente a la Real Sociedad Económica de Amigos del País de Tenerife, constituyen una primorosa selección y convierten el catálogo, aparte de sus muchos méritos intrínsecos, en un volumen sumamente decorativo, vivo ejemplo de lo mucho que se puede hacer cuando Amaltea nutre con recursos públicos abundantes los proyectos culturales. No cabe duda, tal como decíamos, que Viera y Clavijo se merecía este magnífico homenaje celebrado en la capital de España. 